\title{
Enlightenment of Taoist Management Philosophy to Modern Enterprise Management
}

\author{
Shangkun Ji \\ College of Philosophy and Society \\ Guizhou University \\ Guiyang, China \\ jsk19830000@sina.com
}

\begin{abstract}
Modern business management should adapt to the development of the times. Enterprises need to constantly optimize and enhance their own management levels according to their own conditions and external economic and social environment, and keep pace with the times and constantly innovate. Chinese Taoist philosophy contains rich management thoughts, especially the praise of "human" value, which has many valuable inspirations for modern enterprise management innovation. This article attempts to interpret the relationship between the main management ideas contained in Taoist philosophy and the main characteristics of modern enterprise management, and hopes to inspire the modern enterprise management methods.
\end{abstract}

Keywords-Modern business management; Taoism; Management philosophy

\section{INTRODUCTION}

Today, with the development of economic globalization, the economic environment and market environment are becoming more and more complex. In order to better cope with and develop, the management mode of modern enterprises has also undergone an important transformation. The most prominent feature is that enterprises gradually change from the pursuit of economic profit maximization to the pursuit of social responsibility maximization as the highest goal ; From paying attention to the management system and ignoring the value of people in the past, the value of people has changed into valuing and recognizing the value of people. Enterprises regard the overall development of people and the development goals of enterprises as a whole ; From serious and rigid management system to flexible system , and all of which can be nourished in Taoist thought.

\section{THE IMPORTANT CHANGE OF MODERN ENTERPRISE MANAGEMENT SYSTEM}

The important transformation of modern enterprise system has the following three aspects:

\section{A. From Pursuing Profit Maximization to Focusing on Social Benefits.}

The Western mainstream management ideology emphasizes the supremacy of the management system, ignoring the value of human beings, and this is increasingly maladies at the present stage of human social development. The previous management model was to exercise absolute control over people with a strict management system, which greatly limited people's initiative and creativity. However, nowadays, more and more western managers no longer think that the goal of enterprise development is to pursue profit maximization blindly, but instead emphasize the comprehensive social responsibility management of the enterprise. They believe that companies must take corresponding social responsibilities in development and provide strength for social progress.

The famous sociologist and economist Max Weber put forward the famous "ideal type" analysis method [1], and viewed the role of the economy from the overall system of society. He believes that "companies are not an economic model that puts economic efficiency first, but a subsystem that prioritizes social benefits. Because a company only has to produce products that meet the needs of society, and it complies with all social rules in the production process. In order to achieve its economic benefits." The needs of society are like a green hill. Without this green hill, how does the company firewood? According to "Pareto Improvement" in economics, the business owners must ensure that the interests of employees are not compromised, and that the legitimate rights and interests of employees are respected, and that is the greatest benefits of the company are pursued. The company must to realize social benefits must first be considered[2].

\section{B. From the Emphasis on Management Systems to People- Oriented.}

For modern enterprises to pursue long-term development and maintain a place in market competition, the most crucial bargaining chip is talent. The development of enterprises cannot be separated from the introduction and cultivation of talents. The management system of enterprises should also be adapted to the development of human beings and the realization of the greatest value of human beings.

Different from the previous rigid management methods, the modern enterprise system should be based on flexible management and people-oriented, fully consider how to mobilize the enthusiasm of talents and stimulate the creativity of talents, which is also the key to the vitality of the company.

The development of modern enterprises is not an era of closed doors. Enterprises must face cooperation situations that may come from multiple parties, coordination and cooperation 
among various departments within the company, competition and cooperation among external peers, and cooperation between industries. In order to achieve better cooperation and development, the organizational structure and management model of the company must have strong flexibility, which can be adjusted at any time according to the actual situation of the enterprise itself.

\section{By Relying on Leaders' Arbitrariness to Transform into Collective Innovation and Rational Decision-Making.}

In an increasingly competitive economic environment, corporate development decisions must advance with the times and be scientific and rational. Once biased, the consequences will be serious and even make the company in trouble.

Therefore, the rationality of modern enterprise management decision-making lies in brainstorming, reviewing situations with multiple plans and perspectives, and encouraging personnel to carry out innovative thinking on management opinions. It is not possible to make rash decisions based on the personal experience of individual leaders. The company's major decisions should be drawn in a dynamic, open, and diverse system environment.

\section{The EnLightenMEnT OF TAOISt MANAgEMENT PhILOSOPHY ON OPTIMIZING MODERN ENTERPRISE SYSTEM}

\section{A. The Relationship Between the "Tao-Dharma Nature" Idea and "Corporate Social Responsibility Management"}

In the philosophy of Taoism, "Taking Nature as a Way" (The Morality Chapter 26) [3] is the foundation and premise of all ideas. It attributes the causes and results of all things to the natural path. In the Tao Te Ching, the phrase "For I am abstracted from the world, the world from nature, nature from the way, and the way from what is beneath abstraction." (The Morality Chapter 26) is the development of the logical thinking of the Taoist management ideology. The "Nature's Way" is the unifying and reference of all actions.

From the perspective of "Taking Nature as a Way", enterprises are part of the social system. The operation of an enterprise should be based on the sound development of social systems. Moreover, the original intention of the company's founding and the highest goal of development should point to the overall interests of social development. In other words, companies must assume certain social responsibilities.

When the company's own interests and social interests are in conflict and cannot be adjusted, companies should use social interests as their primary purpose. Specifically speaking, enterprises must carry out comprehensive social responsibility management. In the specific management process, enterprises should observe laws and regulations and strengthen social responsibility awareness internally; externally, they must compete with other companies in good faith, pay taxes in accordance with the law, and achieve their own The social responsibility to promote social equity and promote the healthy development of the society, so as to promote the common growth of enterprises and society.

\section{B. The Relationship Between "Governing Without Interruption" and "People-Oriented Talent Management"}

Taoist thought pays great attention to the value of "man". The most basic purpose of Taoism is to interpret the "humanity". Taoism believes that living in the world must follow the path, that is, " Governing Without Interruption." (The Morality Chapter 37)

"Doing nothing" does not mean nothing, but refers to actions and actions that people should "conform to nature." This fully reflects the recognition of human initiative and value in Taoist management philosophy.

The question of human value is the main theme of Taoist thinking. The meaning of Taoist interpretation of man is equivalent to that of Tao, and has the same value as Tao. In other words, people have the natural right and freedom to pursue freedom, equality, and individual liberation. This idea even surpasses the value of Confucian philosophy in the moralization and socialization of human beings. It also differs from that in Western humanism. The infinite exaggeration of human values. The "man" in Taoist thoughts follows the nature and embodies the emancipation and return of human nature. The behavior emphasizes "doing nothing and governing", that is, it does not incite insanity and disobedience, conforms to objective reality, and respects the laws of nature. It means "always inaction but not for" (The Morality Chapter 37).

The famous contemporary philosopher Mr. Sun Zhengyu believes that the "materialization" issue of mankind is the most prominent contemporary and most fundamental "global" issue. In the process of global "marketization", "the independence of people based on the dependence of things" has gradually become the basic mode of existence of contemporary mankind [4]. However, Taoist ideology criticizes people's limitations on human alienation, affirms the pursuit of freedom and equality, and respects the natural harmony of people and society. It is the basis and prerequisite for the sound development of enterprises and society. In the final analysis, business management is the management of people. The understanding and grasp of human nature should be the first. Enterprises should create conditions for people's all-round development, and consciously regard the pursuit of people's all-round development as the highest goal of enterprise development. This is also the social responsibility that companies should undertake. This is also consistent with Taoist thinking's ultimate concern for people, which has a modern enterprise management Important inspiration.

\section{The Relationship Between "Being Born to Nothing, Nothing to Be Born" and "Corporate Innovative Cultural Concept"}

"There is no birth, no birth in there" ( The Morality Chapter 5) is an important proposition in Taoism. Any specific thing ("having") is constantly generated from "nothingness" and continuously transformed from "having" to "nothingness." This idea is a concrete expression of Taoist negative thinking and innovative thinking theory. Innovative management thinking has important guiding significance.

In order to survive, an enterprise must maintain its vitality and be creative. However, Taoism believes that innovation is 
not an out-of-control law. It must be based on the recognition of tradition to promote innovation, that is, to affirm "having" and affirm the role of "nothingness." Enterprises that deeply reconcile the idea of "with or without the other" should understand the operating principles of "creating what others do not have", "doing what others have not done" and "having the latest achievements", winning with "new" and winning with "first". , to "change" to win.

Taoist dialectics and negative thoughts provide important inspirations for the innovation and management of modern corporate culture. If you want to retain your company's youthful vigor, you must inspire corporate people's creativity and ownership. This is the starting point and end result of enterprise innovation management.

\section{CONCLUSION}

In summary, the core ideas in Taoist management philosophy have an important enlightening effect on the gradual transformation of modern enterprise management systems. In summary, the core ideas in Taoist management philosophy have an important enlightening effect on the gradual transformation of modern enterprise management systems. The premise of the Taoist nature is the premise of the Taoist nature. It fully affirms human rights and values, proposes the core of the idea of "doing nothing and govern," and uses it as a concrete guide to the "law of nature." The Taoist management philosophy believes that enterprises should fully initiate social responsibility management and give top priority to social benign development. Moreover, corporate management should fully reflect the dominant position of the people and should realize the full development of people as the highest goal of enterprise development.

The article also points out that for a company to be young, it is necessary to reconcile "needlessness" with negative thoughts and creative thinking, establish an effective enterprise innovation management culture, and inspire corporate people's creativity and struggle spirit. It can be seen that the rich ideological resources in Taoist management philosophy have important implications for the establishment and optimization of modern enterprise management systems and deserve deep reflection.

\section{REFERENCES}

[1] M. Weber, Social Science Methodology, Beijing: Central Compilation \& Translation Press, 2008, pp. 57.

[2] H. Wang, "Improving the Benefits of Human Resource Management from the Perspective of Pareto Optimality," Journal of the Party School of Taiyuan Municipal Committee of the Communist Party of China, pp. 60, June 2010.

[3] B. Wang, Laozi Dao De Jing Shanghai, ZHONGHUA Book Company, 2008.

[4] Z.Y. Sun, "The Predicament of Contemporary Mankind and Theory Consciousness of Philosophy in the New Century," Journal of Social Sciences, pp. 7, September 2003. 